\title{
The Effect of Environmental Conditions on the Mechanical and Thermoelectric Properties of $\mathrm{Bi}_{2} \mathrm{Ca}_{2} \mathrm{Co}_{1.7} \mathrm{O}_{x}$ Textured Rods
}

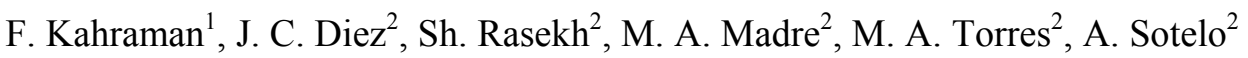 \\ ${ }^{1}$ Department of Mechatronics Engineering, Faculty of Tarsus Technology, University of \\ Mersin, Mersin, Turkey \\ ${ }^{2}$ Instituto de Ciencia de Materiales de Aragón (CSIC-Universidad de Zaragoza), Ma de Luna 3 , \\ 50018 Zaragoza, Spain.
}

\begin{abstract}
The effect of environmental conditions on the microstructural, mechanical and thermoelectric properties of highly textured $\mathrm{Bi}_{2} \mathrm{Ca}_{2} \mathrm{Co}_{1.7} \mathrm{O}_{\mathrm{x}}$ thermoelectric materials was investigated by powder $x$-ray diffraction, scanning electron microscopy, three point bending test, electrical resistivity, and thermopower measurements. Textured thin rods were directionally grown from the melt through a laser floating zone melting technique. The mechanical and thermoelectric properties of $\mathrm{Bi}_{2} \mathrm{Ca}_{2} \mathrm{Co}_{1.7} \mathrm{O}_{\mathrm{x}}$ were determined as a function of two different environmental conditions, air and water. Flexural strength data showed that these oxide materials possess an unsuspected degradation resistance. These good results have been related to the presence of a very thin $(\sim 250 \mu \mathrm{m})$ low porosity region and relatively small grain sizes, which avoids the internal degration by water infiltration through the porosity. Moreover, thermoelectric performances, evaluated through the power factor are maintained practically unchanged, independently of the environmental conditions.
\end{abstract}

Keywords: $\mathrm{Bi}_{2} \mathrm{Ca}_{2} \mathrm{Co}_{1.7} \mathrm{O}_{\mathrm{x}}$, laser floating zone, flexural strength, power factor 


\section{Introduction}

Thermoelectric (TE) power generation is an appropriate and promising method to convert wasted heat into electrical energy due to the Seebeck effect, which allows transforming a temperature gradient, through a thermoelectric device, into electrical potential. On the other hand, these thermoelectric devices can also be used for cooling/heating purposes due to the Peltier effect [1-4].

Environmental challenges, such as global warming, growing demand on energy, and diminishing oil sources have accelerated research on alternative energy sources and conversion methods. Meanwhile, a significant amount of energy is wasted, mainly as heat, during energy conversion processes due to technological limitations. TE materials could increase the overall efficiency of the conventional energy conversion systems reducing, at the same time, the demand on fossil fuels and natural resources and also contributing to the reduction of greenhouse gases.

The performances of these TE materials are usually quantified by the dimensionless figure of merit, ZT, which is defined as $\mathrm{TS}^{2} / \rho \kappa$ (where $\mathrm{S}$ is the Seebeck coefficient, $\rho$ the electrical resistivity, $\kappa$ the the thermal conductivity and $\mathrm{T}$ the absolute temperature). On the other hand, other common quantification of TE performances is the power factor, $\mathrm{PF}$, defined as, $\mathrm{S}^{2} / \rho$. As a consequence, a high performance TE material should possess a high Seebeck coefficient with low electrical resistivity and low thermal conductivity [5].

Nowadays, TE devices based on semiconductor materials $\left(\mathrm{Bi}_{2} \mathrm{Te}_{3}, \mathrm{Sb}_{2} \mathrm{Te}_{3}, \ldots\right)$ have been industrially applied, e.g. in vehicle exhausts. Due to the intrinsic characteristics of this type of compounds (chemical degradation, evaporation of heavy metals, etc.), they should not be used in devices working at relatively high temperatures. These limitations have been overwhelmed by the discovery of attractive thermoelectric properties in $\mathrm{NaCo}_{2} \mathrm{O}_{4}[6]$, which has attracted much attention on CoO-based ceramic compounds. The intense research work performed on these oxides led to the discovery of high thermoelectric performances in other related materials as $\mathrm{Ca}_{3} \mathrm{Co}_{4} \mathrm{O}_{9}, \mathrm{Bi}_{2} \mathrm{Sr}_{3} \mathrm{Co}_{2} \mathrm{O}_{9}$, $\mathrm{Bi}_{2} \mathrm{Ca}_{2} \mathrm{Co}_{2} \mathrm{O}_{\mathrm{x}} \mathrm{Bi}_{2} \mathrm{Sr}_{2} \mathrm{Co}_{1.8} \mathrm{O}_{\mathrm{x}}$ and $\mathrm{Bi}_{2} \mathrm{Ca}_{2} \mathrm{Co}_{1.7} \mathrm{O}_{\mathrm{x}}$ [7-12].

These cobaltite compounds can be described by a monoclinic crystal structure, which is, in turn, composed by an alternate stacking of two different layers, a common conductive $\mathrm{CdI}_{2}$-type $\mathrm{CoO}_{2}$ layer with a two-dimensional triangular lattice and an insulating rocksalt-type (RS) block layer. Both sublattices (RS block and $\mathrm{CdI}_{2}$-type layer) possess common a- and c-axis lattice parameters and $\beta$ angles but different $b$-axis length, 
causing a misfit along the b-direction. As a consequence of their crystal structure, layered cobaltites are characterized by a high anisotropy which leads to the formation of plate-like grains during the crystallization process $[9,13]$. This feature can be exploited in the improvement of their electrical properties, when an adequate grain orientation is produced. Such grain alignment would allow attaining macroscopic properties comparable to those obtained on single crystals. Numerous methods have been reported to be efficient to obtain a good grain alignment, such as spark plasma sintering [14], sinter-forging [15], templated grain growth (TGG) [16], laser floating zone (LFZ) [17] or electrically assisted laser floating zone (EALFZ) [18].

It is well known that some oxide materials can chemically react with water, and their reactivity is usually increased by the presence of alkaline metals and/or alkaline earths. Chemical reactivitiy causes degradation, leading to the decrease of their mechanical and electrical properties. Thus, it is necessary to take into account their reactivity to moisture for any practical application [19].

The aim of the present work is studying the effect of the environmental conditions on the structural, mechanical and thermoelectric properties of textured $\mathrm{Bi}_{2} \mathrm{Ca}_{2} \mathrm{Co}_{1.7} \mathrm{O}_{\mathrm{x}}$ ceramics directionally grown by the LFZ technique.

\section{Experimenta}

$\mathrm{Bi}_{2} \mathrm{Ca}_{2} \mathrm{Co}_{1.7} \mathrm{O}_{\mathrm{x}}$ TE ceramics were prepared by the conventional solid state method using commercial $\mathrm{Bi}_{2} \mathrm{O}_{3}$ (Panreac, 98+\%), $\mathrm{CaCO}_{3}$ (Panreac, 98+\%), and $\mathrm{Co}_{2} \mathrm{O}_{3}$ (Aldrich, $98+\%$ ) powders. They were weighed in the adequate proportions, mixed and ball milled at $300 \mathrm{rpm}$ for $30 \mathrm{~min}$, in acetone media. The resulting suspension was placed into a glass container and dried using an IR evaporation system. The dry powder has then been thermally treated twice at $750{ }^{\circ} \mathrm{C}$ and $800{ }^{\circ} \mathrm{C}$ for about $12 \mathrm{~h}$ under air, with an intermediate manual milling, in order to assure the complete decomposition of the carbonates. This thermal treatment is necessary and it has been designed specifically to avoid the presence of carbonates in the following steps, as they would produce bubbles in the melt, disturbing the solidification front. These powders were then used to prepare cylindrical precursors, $120 \mathrm{~mm}$ long and 2-3 $\mathrm{mm}$ diameter by cold isostatic pressing into latex tubes at an applied pressure of $200 \mathrm{MPa}$ for around $2 \mathrm{~min}$. Precursor rods were used as feed in a LFZ equipment, where they were grown at $30 \mathrm{~mm} / \mathrm{h}$ using a continuous power Nd:YAG laser $(\lambda=1.064 \mu \mathrm{m})$, under air, as reported previously [17]. Finally, after the texturing process, long and geometrically homogeneous textured 
cylindrical rods have been produced. These bars were cut into pieces ( $\sim 15 \mathrm{~mm}$ long) for their characterization. The main phases identification was carried out using powder Xray diffraction in a Rigaku D/max-B device, working with $\mathrm{Cu} \mathrm{K}_{\alpha}$ radiation and $2 \theta$ ranging between 5 and 40 degrees. The fractured surfaces were examined in a scanning electron microscope (JEOL JSM 6400). Mechanical characterization has been performed by flexural strength, using the three-point bending test in an Instron 5565 machine with a $10 \mathrm{~mm}$ loading span fixture. The flexural strength of textured $\mathrm{Bi}_{2} \mathrm{Ca}_{2} \mathrm{Co}_{1.7} \mathrm{O}_{\mathrm{x}}$ thin rods was measured as a function of the environmental conditions, air and water, at room temperature. Loading rates spanning three orders of magnitude $(1,10$ and $100 \mu \mathrm{m} / \mathrm{min}$ ) were used to explore their susceptibility to the environmental conditions. The rods tested in water conditions were immersed in distilled water during $1 \mathrm{~h}$ before the test. A drop of distilled water added with a syringe, covered the central section of the rods during mechanical tests to ensure that the fracture region was immersed in water during the test. The flexural strength was computed from the maximum load achieved in the test according to the strength of materials theory for an elastic beam of circular section. Thermoelectric characterization has been performed in the as-grown samples, as well as in $24 \mathrm{~h}$ and 24 days water immersed ones. Electrical resistivity and Seebeck coefficient were simultaneously determined in a LSR-3 measurement system (Linseis $\mathrm{GmbH}$ ) between room temperature and $650{ }^{\circ} \mathrm{C}$ under $\mathrm{He}$ atmosphere. Power factor has been calculated in order to determine the samples performances.

\section{Results and Discussion}

Powder X-ray diffraction (XRD) patterns have been systematically recorded in order to identify the different phases in the thermoelectric materials. Fig.1. shows a representative XRD pattern for the $\mathrm{Bi}_{2} \mathrm{Ca}_{2} \mathrm{Co}_{1.7} \mathrm{O}_{\mathrm{x}}$ samples, performed in the as-grown samples. As it can be observed in the figure, most of the peaks correspond to the $\mathrm{Bi}_{2} \mathrm{Ca}_{2} \mathrm{Co}_{1.7} \mathrm{O}_{\mathrm{x}}$ thermoelectric phase indicated by their diffraction plane in the figure, in agreement with previously reported data [20]. Moreover, there are minor peaks associated to the $\mathrm{Bi}_{6} \mathrm{Ca}_{4} \mathrm{O}_{13}$ non-thermoelectric secondary phase (indicated by *), as expected from an incongruent melt, and in agremeent with previous data [21]. Microstructural studies of the transversal broken surfaces have shown that the microstructure is nearly the same for all samples. A typical $\mathrm{Bi}_{2} \mathrm{Ca}_{2} \mathrm{Co}_{1.7} \mathrm{O}_{\mathrm{x}}$ fractured surface of samples is displayed in Fig. 2 (in this case, they correspond to the $24 \mathrm{~h}$ water 
immersed ones). As it can be clearly observed in the figure, two different regions can be distinguished, the outer and inner ones (separated by a dashed line in Fig. 2a). The inner region is composed by large and very well aligned grains while the outer one, with $~ 250$ $\mu \mathrm{m}$ thickness, possesses small grains and very low porosity. The great microstructural difference between both regions can be seen in the higher magnification micrograph displayed in Fig.2b. The very low porosity of the outer region is of the main importance in these samples, as it can act as a protective layer against water diffusion into the internal region, minimizing the chemical degradation.

Mechanical characterization of $\mathrm{Bi}_{2} \mathrm{Ca}_{2} \mathrm{Co}_{1.7} \mathrm{O}_{\mathrm{x}}$ samples has been performed by the threepoint bending tests. The flexural strength has been calculated by using Eq. (1).

$\sigma_{f}=\frac{8 F L}{\pi d^{3}}$

where $\sigma_{\mathrm{f}}$ is the flexural strength $(\mathrm{MPa}), \mathrm{F}$ the applied load $(\mathrm{N}), \mathrm{L}$ the span $(\mathrm{mm})$, and $\mathrm{d}$ the bar diameter (mm)

In order to evaluate the mechanical behavior evolution with the environment, flexural strength tests were made on different environment (air and water) and loading rates (1,10 and $100 \mu \mathrm{m} / \mathrm{min}) .10$ samples for each condition were used to minimize errors. The experimental data determined from the tests at different loading rates are displayed in Table 1, where the mean values of $\sigma_{\mathrm{f}}$ are displayed, together with their corresponding standard errors. Moreover, Weibull parameter, $\mathrm{m}$, calculated from the data obtained in the three point bending experiments is given in Table 1. The brittle nature of these ceramic materials is reflected in the Weibull parameter [22]. An interesting resut shown in this table is that the mean flexural strength values are not so different for each of the environmental conditions and loading rates. When observing the data obtained in samples measured under air, a very slight dependence of the mean flexural strength with the loading rate can be found ( $\Delta \approx 6 \%$, from 113.1 to $120.2 \mathrm{MPa}$ ), while there is slightly higher in the case of the water immersed samples $(\Delta \approx 11 \%$, from 97.2 to $108.5 \mathrm{MPa})$. Moreover, mean flexural strength values are slightly lower for the water aged samples than for the as-grown ones, confirming some damage produced by water.

The flexural strength of the samples as a function of loading rate is represented in Fig.3. As it can be clearly seen mean flexural strength values decrease when loading rate is reduced due to a subcritical crack growth process. This change can be related to the chemical degradation with environmental water vapour for the dry samples, while it is due to a higher interaction of water with the samples in the water immersed ones. This 
behaviour is in agreement with a stress corrosion cracking process which allows the interpretation of the mechanical behavior of this material. The stable growth of cracks under applied stresses lower than that for fast fracture (slow crack growth, SCG) is usually studied by means of a power-law function [23,24].

$v=\frac{d a}{d t}=A K_{l}^{n}$

where $\mathrm{v}$, a and $\mathrm{t}$ are the crack growth velocity, crack size and time, respectively. $\mathrm{K}_{\mathrm{I}}$ is the stress intensity factor. A and $\mathrm{n}$ are parameters depending on the material and environment [22]. The $n$ values have been computed from the slope of the $\log \left(\sigma_{\mathrm{f}}\right)$ versus $\log (d \varepsilon / d t)$, where $(d \varepsilon / d t)$ is the strain rate used in the different tests. No significant differences have been found for the flexural strength when the flexure tests were performed in air at the three different loading rates, with $\mathrm{n}$ around 75 . On the other hand, samples immersed in water show a slight dependence with the loading rate, and $\mathrm{n}$ about 41 . This value is very close to the previously obtained on other plate-like functional ceramics $(\mathrm{n}=42), \mathrm{Bi}_{2} \mathrm{Sr}_{2} \mathrm{CaCu}_{2} \mathrm{O}_{\mathrm{x}}$, grown by the same technique and tested in the same conditions [24]. These results confirm the effectiveness of LFZ technique to improve the environmental degradation resistance of these textured materials due to the formation of a very low porosity outer region.

The temperature dependence of the resistivity for the different samples is represented in Fig.4. As can be clearly seen in figure, all curves show the same semiconductor-like behaviour $(\delta \rho / \delta \mathrm{T}<0)$ in the whole temperature range, in agreement with previous studies [12,25]. Moreover, the electrical resistivity increases with the water inmersion time, due to the slight superficial degradation. The measured resistivity values, 71,82 and $89 \mathrm{~m} \Omega \mathrm{cm}$, at room temperature (RT) for as-grown, and water immersed for $24 \mathrm{~h}$ and 24 days samples, respectively, are lower than the reported ones for sintered specimens [13,25], which show resistivities around 80-100 $\mathrm{m} \Omega \mathrm{cm}$ at RT. The obtained value for the as-grown samples is the same for textured materials (around $70 \mathrm{~m} \Omega . \mathrm{cm}$ ) at RT [17].

The Seebeck coefficient variation as a function of temperature for all samples is shown in Fig.5. In the plot, it can be clearly seen that the sign of the Seebeck coefficient is positive in the whole measured temperature range, which confirms a conduction mechanism mainly governed by holes. The values of the Seebeck coefficient increase 
when temperature is raised, with similar behaviour for all the samples. On the other hand, the slight superficial degradation produced by the water immersion, is reflected is an increase of the Seebeck coefficient, compared with the measured in the as-grown samples. This is a clear indication that immersing time does not appreciably affect the thermopower values. The measured Seebeck coefficient 190, 212 and $207 \mu \mathrm{V} / \mathrm{K}$, at RT for as-grown, and water immersed for $24 \mathrm{~h}$ and 24 days samples, respectively, are higher than those reported for solid state sintered materials $[13,25]$ (usually about 150 $\mu \mathrm{V} / \mathrm{K}$ ). These values are close to the obtained in textured materials (around $200 \mu \mathrm{V} / \mathrm{K}$ ) at RT [17].

The thermoelectric performances of samples were evaluated through the PF values. They were calculated from the electrical resistivity and Seebeck coefficient data, and are presented as a function of temperature in Fig. 6. In this plot, it can be observed that $\mathrm{PF}$ incresases when the temperature is raised with similar behaviour for all the samples. As-grown and $24 \mathrm{~h}$ water immersed samples show approximately the same value, while it is slightly lower for those immersed in water for 24 days. This evolution is a clear indication of the protective effect against water degradation of the external layer in these textured samples. The obtained PF values $0.050,0.050$, and $0.048 \mathrm{~mW} / \mathrm{K}^{2} \mathrm{~m}$, for as-grown, and water immersed for $24 \mathrm{~h}$ and 24 days, respectively, are higher than those obtained for sintered specimens reported in the literature $\left(\sim 0.03 \mathrm{~mW} / \mathrm{K}^{2} \mathrm{~m}\right)[13,25]$ and slightly higher than for textured materials in the literature $\left(\sim 0.045 \mathrm{~mW} / \mathrm{K}^{2} \mathrm{~m}\right)$ [17].

\section{Conclusions}

The influence of environment susceptibility and loading rate on the flexure strength of textured $\mathrm{Bi}_{2} \mathrm{Ca}_{2} \mathrm{Co}_{1.7} \mathrm{O}_{\mathrm{x}}$ rods processed by the $\mathrm{LFZ}$ was investigated by means of three point bending tests in air and water. Also, the effect of environmental conditions on termoelectric properties of this material was investigated. No significant differences have been found in the flexural strength when the flexure tests were performed in air at different loading rates, with an $n$ value of 75 . It was found that the flexural strength of samples immersed in water slighty depends on the loading rate, with an $\mathrm{n}$ value of 41 . All the obtained data from three point bending test show that LFZ textured materials possess a high degradation resistance due to the high density of their external part ( $250 \mu \mathrm{m}$ thickness) which protects the inner one against chemical degradation with 
water. As a consequence, the thermoelectric performances, evaluated through the power factor, are maintaned practically unchanged.

\section{Acknowledgements}

The authors acknowledge financial support from the Gobierno de Aragón and the Fondo Social Europeo (Consolidated Research Groups T12 and T87) and MINECO-FEDER (Project MAT2013-46505-C3-1-R). The technical contribution of C. Estepa, and C. Gallego are also acknowledged. F. Kahraman acknowledges a financial grant from the Council of Higher Education (YÖK) in Turkey for international mobility. Authors would like to acknowledge the use of Servicio General de Apoyo a la InvestigaciónSAI, Universidad de Zaragoza.

\section{References}

1. U. Erturun, K. Erermis, K. Mossi, Effect of various leg geometries on thermomechanical and power generation performance of thermoelectric devices, Appl. Thermal Eng. 73 (2014) 126-139.

2. J. Xiaodong, G. Yuanwen, Estimation of thermoelectric and mechanical performances of segmented thermoelectric generators under optimal operating conditions, Appl. Thermal Eng. 73 (2014) 333-340.

3. J.C. Diez, E. Guilmeau, M.A. Madre, S. Marinel, S. Lemonnier, A. Sotelo, Improvement of $\mathrm{Bi}_{2} \mathrm{Sr}_{2} \mathrm{Co}_{1.8} \mathrm{O}_{\mathrm{x}}$ thermoelectric properties by laser floating zone texturing, Solid State Ionics 180 (2009) 827-830.

4. T.M. Tritt, M.A. Subramanian, Thermoelectric materials, phenomena, and applications: A bird's eye view, J.MRS Bull. 31 (2006) 188-198.

5. D.M. Rowe, in: D.M. Rowe (Ed.), Thermoelectrics Handbook: Macro to Nano. 1 st ed, CRC Press, Boca Raton, FL, 2006, pp 1-7.

6. I. Terasaki, Y. Sasago, K. Uchinokura, Large thermoelectric power in $\mathrm{NaCo}_{2} \mathrm{O}_{4}$ single crystals, Phys Rev B 56 (1997) 12685-12687. 
7. Sh. Rasekh, M.A. Madre, A. Sotelo, E. Guilmeau, S. Marinel, J.C. Diez, Effect of Pb substitution on the thermoelectrical properties of textured $\mathrm{Bi}_{2} \mathrm{Ca}_{2} \mathrm{Co}_{1.7} \mathrm{O}_{\mathrm{y}}$ ceramics prepared by a polymer solution method, Bol. Soc. Esp. Ceram. 49 (2010) 89-94.

8. D. Kenfaui, D. Chateigner, M. Gomina, and J.G. Noudem, Texture, mechanical and thermoelectric properties of $\mathrm{Ca}_{3} \mathrm{Co}_{4} \mathrm{O}_{9}$ ceramics, J. Alloys Compd. 490 (2010) 472-479. 9. J.C. Diez, Sh. Rasekh, G. Constantinescu, M.A. Madre, M.A. Torres, A. Sotelo, Effect of annealing on the thermoelectric properties of directionally grown $\mathrm{Bi}_{2} \mathrm{Sr}_{2} \mathrm{Co}_{1.8} \mathrm{O}_{\mathrm{x}}$ ceramics, Ceram. Int. 38 (2012) 5419-5424.

10. M.A. Madre, F.M. Costa, N.M. Ferreira, A. Sotelo, M.A. Torres, G. Constantinescu, Sh. Rasekh, J.C. Diez, Preparation of high-performance $\mathrm{Ca}_{3} \mathrm{Co}_{4} \mathrm{O}_{9}$ thermoelectric ceramics produced by a new two-step method, J. Eur. Ceram. Soc. 33 (2013) 17471754.

11. M.A. Madre, Sh. Rasekh, J.C. Diez, A. Sotelo, New solution method to produce high performance thermoelectric ceramics: A case study of Bi-Sr-Co-O, Mater. Lett. 64 (2010) 2566-2568.

12. Sh. Rasekh, N.M. Ferreira, F.M. Costa, G. Constantinescu, M.A. Madre, M.A. Torres, J.C. Diez, A. Sotelo, Development of a new thermoelectric $\mathrm{Bi}_{2} \mathrm{Ca}_{2} \mathrm{Co}_{1.7} \mathrm{O}_{\mathrm{x}}+\mathrm{Ca}_{3} \mathrm{Co}_{4} \mathrm{O}_{9}$ composite, Scr. Mater. 80 (2014) 1-4.

13. A. Maignan, S. Hébert, M. Hervieu, C. Michel, D. Pelloquin, D. Khomskii, Magnetoresistance and magnetothermopower properties of $\mathrm{Bi} / \mathrm{Ca} / \mathrm{Co} / \mathrm{O}$ and $\mathrm{Bi}(\mathrm{Pb}) / \mathrm{Ca} / \mathrm{Co} / \mathrm{O}$ misfit layer cobaltites, J. Phys. Condens Matter. 15 (2003) 2711-23.

14. Y. Zhang, J. Zhang, Q. Lu, Synthesis of highly textured $\mathrm{Ca}_{3} \mathrm{Co}_{4} \mathrm{O}_{9}$ ceramics by spark plasma sintering, Ceram. Int. 33 (2007) 1305-1308.

15. M. Prevel, O. Perez, J.G. Noudem, Bulk textured $\mathrm{Ca}_{2.5}(\mathrm{RE})_{0.5} \mathrm{Co}_{4} \mathrm{O}_{9}(\mathrm{RE}: \mathrm{Pr}, \mathrm{Nd}$, $\mathrm{Eu}, \mathrm{Dy}$ and $\mathrm{Yb}$ ) thermoelectric oxides by sinter-forging, Solid State Sci. 9 (2007) 231235.

16. H. Itahara, C. Xia, J. Sugiyama, T. Tani, Fabrication of textured thermoelectric layered cobaltites with various rock salt-type layers by using beta- $\mathrm{Co}(\mathrm{OH})_{2}$ platelets as reactive templates, J. Mater. Chem. 14 (2004) 61-66.

17. A. Sotelo, E. Guilmeau, M.A. Madre, S. Marinel, S. Lemonnier, J.C. Diez, $\mathrm{Bi}_{2} \mathrm{Ca}_{2} \mathrm{Co}_{1.7} \mathrm{O}_{\mathrm{x}}$ thermoelectric ceramics textured by laser floating zone method, Bol. Soc. Esp. Ceram. 47 (2008) 225-228. 
18. N.M. Ferreira, Sh. Rasekh, F.M. Costa, M.A. Madre, A. Sotelo, J.C. Diez, M.A. Torres, New method to improve the grain alignment and performance of thermoelectric ceramics, Mater. Lett. 83 (2012) 144-147.

19. D. Lee, Sr. R.A. Kondrate, J.A. Taylor The environmental degradation mechanism and protective organic thin film coatings on a high-temperature bismuth-cuprate superconductors, Physica C 350 (2001) 1-16.

20. Y. Tanaka, T. Fujii, M. Nakanishi, Y. Kusano, H. Hashimoto, Y. Ikeda, Systematic study on synthesis and structural, electrical transport and magnetic properties of $\mathrm{Pb}$ substituted Bi-Ca-Co-O misfit-layer cobaltites, Solid State Commun. 141 (2007) 122126.

21. J.B. Parise, C.C. Torardi, M.H. Whango, C.J. Rawn, R.S. Roth, B.P. Burton, $\mathrm{Ca}_{4} \mathrm{Bi}_{6} \mathrm{O}_{13}$, a compound containing an unusually low bismuth coordination number and short Bi-Bi contacts, Chem. Mater. 2 (1990) 454-458.

22. M.A. Madre, Sh. Rasekh, J.C. Diez, A. Sotelo, Dynamic fatigue behaviour of agdoped Bi-2212 textured thin rods, J. Phys.: Conf. Ser. 153 (2009) 0122021

23. D. Munz, T. Fett, Ceramics: Mechanical Properties, Failure Behaviour, Materials Selection. 1st ed. Springer, Berlin, 2001, pp 78-81.

24. J.C. Diez, A. Sotelo, M. Mora, H. Amaveda M.A. Madre, Stress corrosion cracking of Bi-2212 thin rods, J. Eur. Ceram. Soc. 27 (2007) 3963-3966.

25. E.Guilmeau, M.Mikami, R.D. Funahashi, D. Chateigner, Synthesis and thermoelectric properties of $\mathrm{Bi}_{2.5} \mathrm{Ca}_{2.5} \mathrm{Co}_{2} \mathrm{O}_{\mathrm{x}}$ layered cobaltites, J. Mater. Res. 20 (4) (2005) 1002-1008. 


\section{Figure Captions}

Fig. 1. XRD plot of the $\mathrm{Bi}_{2} \mathrm{Ca}_{2} \mathrm{Co}_{1.7} \mathrm{O}_{\mathrm{x}}$ samples. Peaks are marked with $*$ for the $\mathrm{Bi}_{6} \mathrm{Ca}_{4} \mathrm{O}_{13}$ secondary phase

Fig. 2. Typical fracture surface of a textured $\mathrm{Bi}_{2} \mathrm{Ca}_{2} \mathrm{Co}_{1.7} \mathrm{O}_{\mathrm{x}}$ ceramic: (a) general view, (b) detail of the inner and outer regions. The microstructures shown in this figure corresponds to the $24 \mathrm{~h}$ water immersed samples.

Fig. 3. Flexural strength of $\mathrm{Bi}_{2} \mathrm{Ca}_{2} \mathrm{Co}_{1.7} \mathrm{O}_{\mathrm{x}}$ materials as a function of the loading rate, measured in different environments: a) air; and b) water. The dashed lines are passing through the mean strength values for each loading rate and are a guide for eyes.

Fig. 4. Temperature dependence of the electrical resistivity as a function of environmental conditions. (•) As-grown, water immersed for ( $\bullet$ ) 24h and $(\diamond) 24$ days samples

Fig. 5. Temperature dependence of the Seebeck coefficient as a function of environmental conditions. (•) As-grown, water immersed for ( $\bullet$ ) 24h and $(\diamond) 24$ days samples

Fig. 6. Temperature dependence of the PF as a function of environmental conditions.

$(\bullet)$ As grown, water immersed for $(\bullet) 24 \mathrm{~h}$ and $(\bullet) 24$ days samples 
Table

Mechanical properties of $\mathrm{Bi}_{2} \mathrm{Ca}_{2} \mathrm{Co}_{17} \mathrm{O}_{x}$ thermoelectric ceramics.

\begin{tabular}{rlrc}
\hline Loading rate $(\mu \mathrm{m} / \mathrm{min})$ & Environment & $\sigma_{f}(\mathrm{MPa})$ & Weibull parameter $(\mathrm{m})$ \\
\hline 1 & Air & $113.1 \pm 4.5$ & 9.4 \\
10 & Air & $113.4 \pm 5.4$ & 7.6 \\
100 & Air & $120.2 \pm 6.9$ & 6.4 \\
1 & Water & $97.2 \pm 4.0$ & 9.4 \\
10 & Water & $101.3 \pm 6.6$ & 6.2 \\
100 & Water & $108.5 \pm 2.1$ & 17 \\
\hline
\end{tabular}


Figure 1

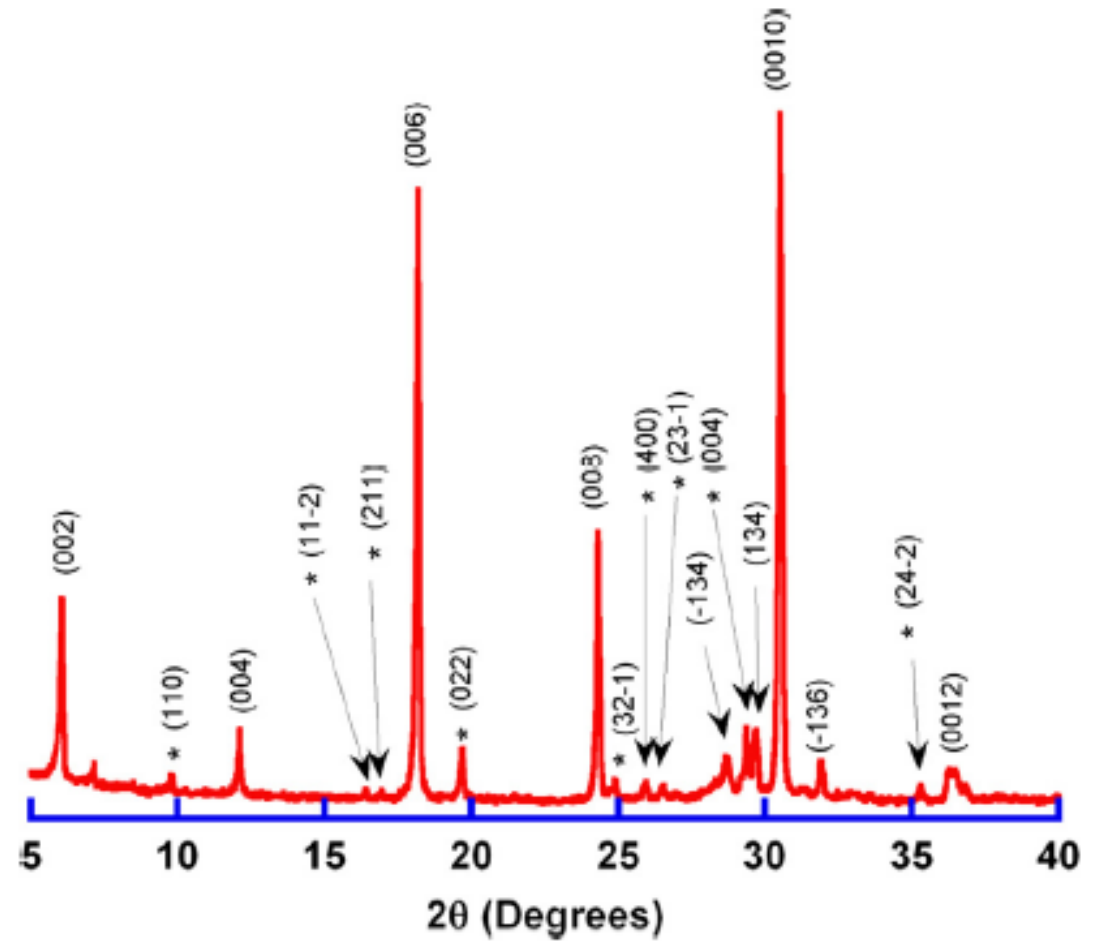


Figure 2
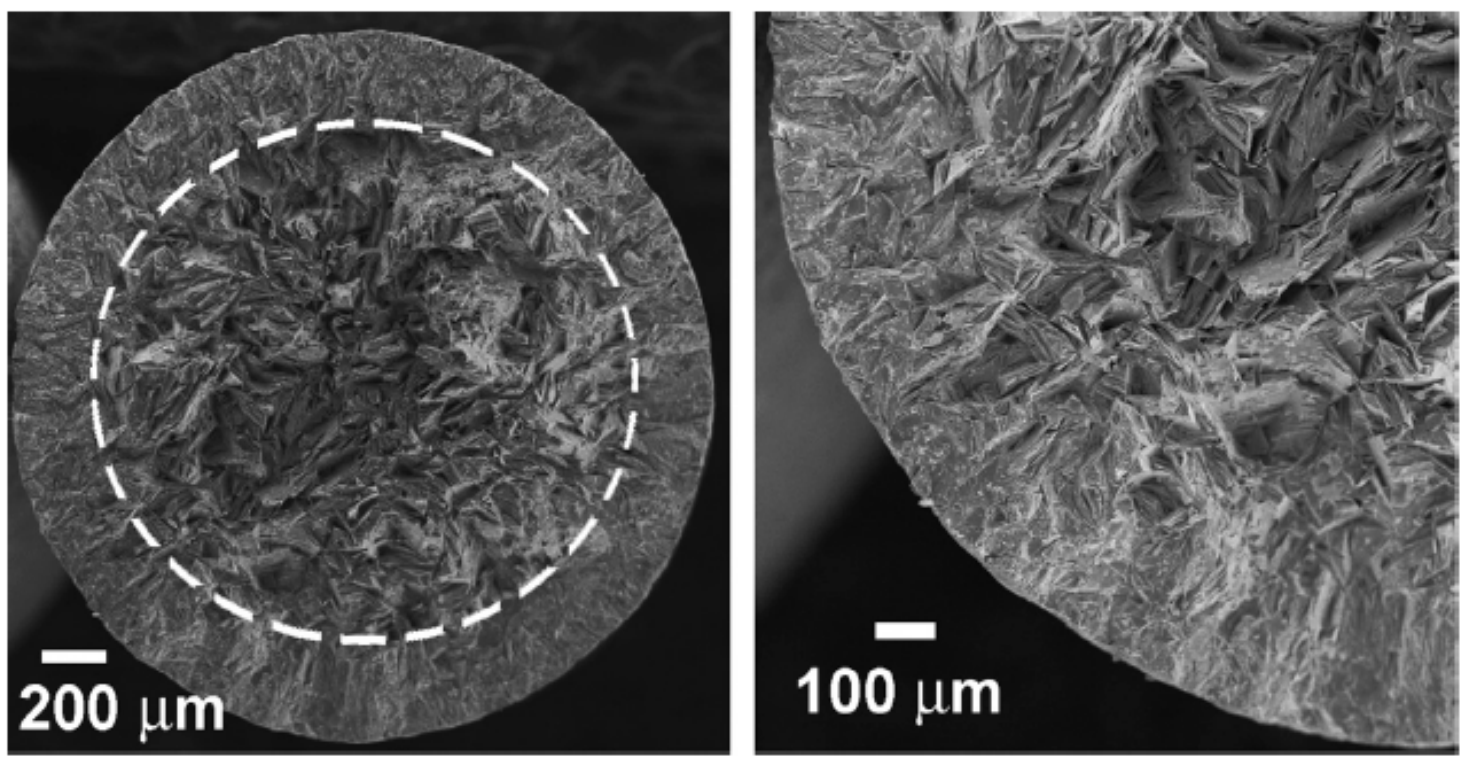
Figure 3
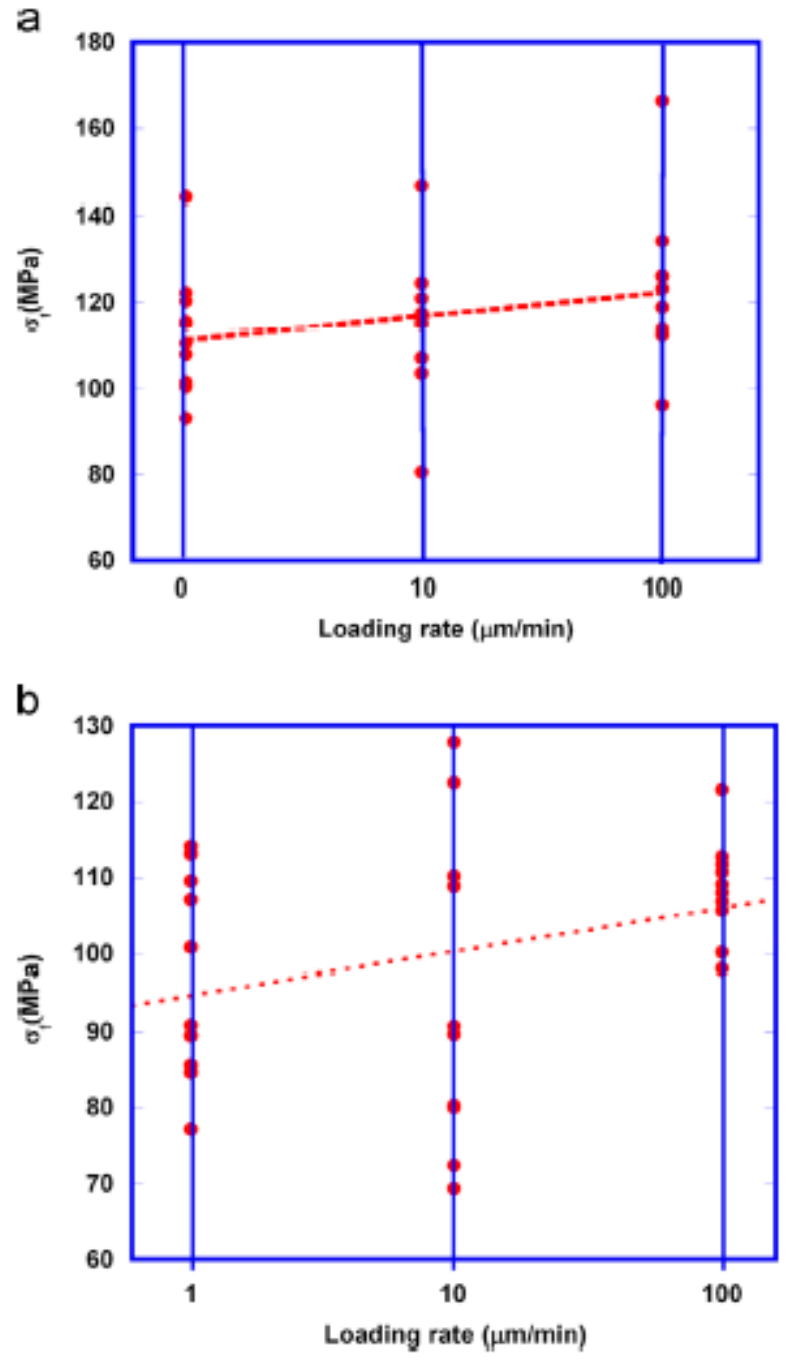
Figure 4

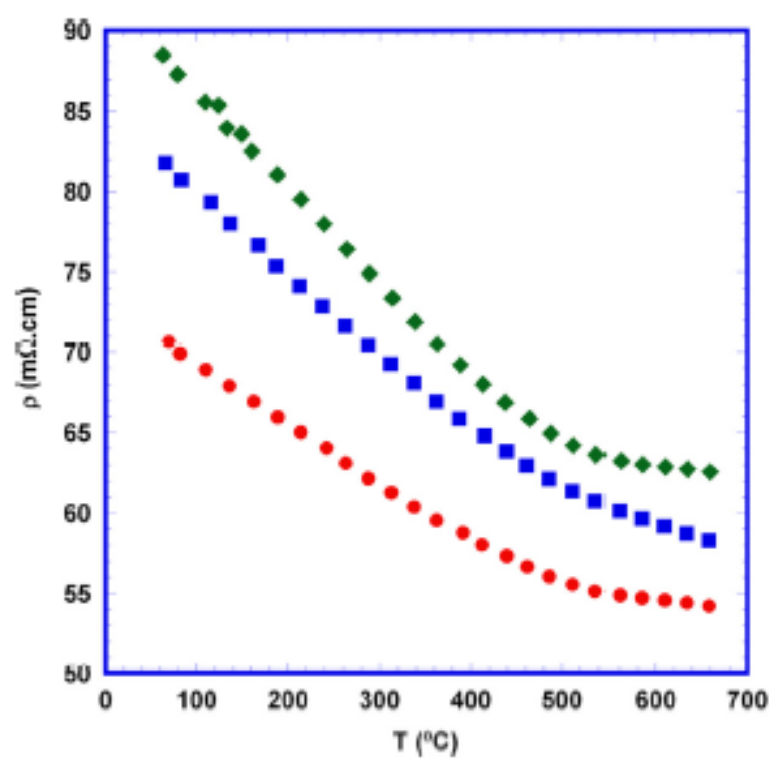


Figure 5

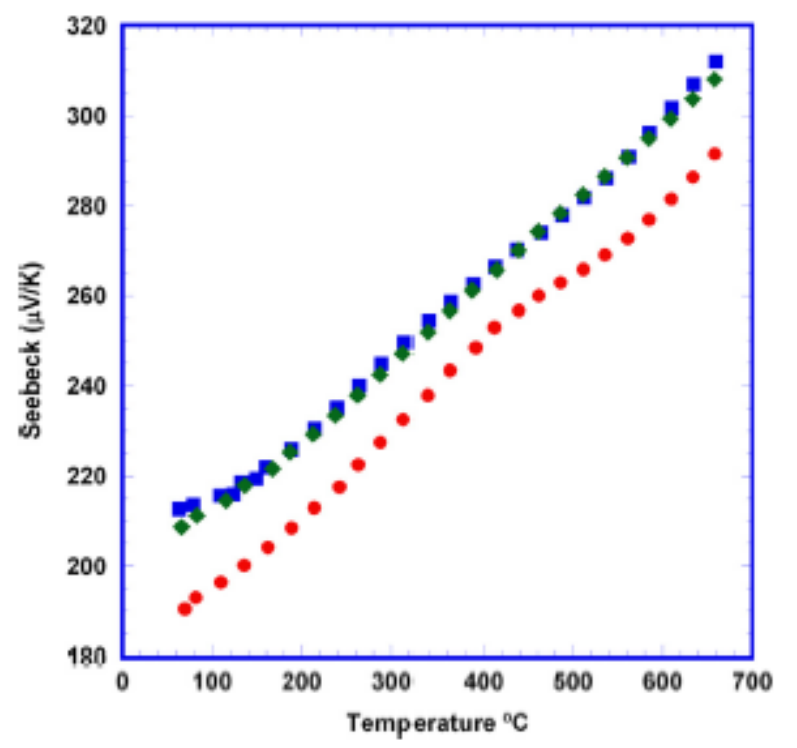


Figure 6

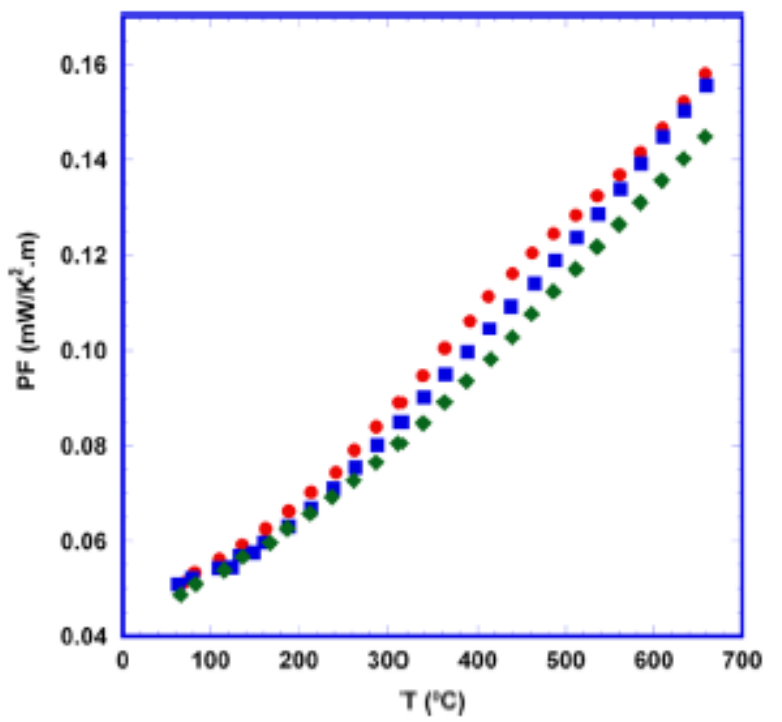

